\title{
Credit Courses on University Teaching for Graduate Students in Canadian Universities
}

\section{SERGE PICCININ`\& MICHELLE PICARD*}

\begin{abstract}
The results of a national survey of credit courses on university teaching and learning for graduate students in Canadian universities are reported. Six universities offer these semester length credit courses. All of these courses are available to all graduate students, but limited resources severely restrict the numbers who can actually take the courses. Half of the credit courses are sponsored by faculties of graduate studies. A range of benefits of these courses and suggested factors to consider in initiating similar courses are noted.
\end{abstract}

\section{Résumé}

Cette étude traite des résultats d'un sondage national sur les cours crédités de pédagogie universitaire qui sont offerts aux étudiants et étudiantes de deuxième et troisième cycle par les universités canadiennes. Six universités offrent actuellement des cours d'un semestre, dont la moitié sont parrainés par des facultés d'études supérieures. Toutefois, bien que la plupart des cours soient accessibles à tous les étudiants des cycles supérieurs, le manque de ressources limite considérablement les inscriptions. On décrit les avantages de ces cours et les facteurs dont il faut tenir compte pour les mettre en place.

* University of Ottawa 
There has been interest in the preparation of graduate students for teaching for some time (Andrews, 1985). However, the emphasis on Teacher Assistant (TA) training has largely been accelerated since the late 1980s in both Canada (Piccinin, Farquharson, \& Mihu, 1993) and the United States (Sheridan, 1991; Wilkening, 1991). As explained by Hiiemae, Lambert, and Hayes (1991), training programs for teaching assistants, at least in the United States, were rare five years ago. Today, many universities have established training programs, while others are considering doing so and are examining the options.

The impetus for the creation of such teaching programs has come from two major concerns. First, the training of teaching assistants has been motivated by a desire to improve undergraduate education (Nyquist, Abbott, Wulff, \& Sprague, 1991; Wilkening, 1991). Second, there has been a growing recognition that the failure to train teaching assistants may cost the professoriate by contributing to the shortage of those opting for a career in academia (Hiiemae et al., 1991; Nyquist et al., 1991; Wilkening, 1991). Recently, the Report of the Commission of Inquiry on Canadian University Education (Smith, 1991) has echoed these concerns.

Because of the above mentioned concerns, the issue of TA training, and specifically of the various approaches to training, has received considerable attention (e.g., Nyquist, Abbott, \& Wulff, 1989; Piccinin et al., 1993). Hiiemae et al. (1991) distinguish two approaches to training: intensive and protracted. They describe intensive programs as pre-semester or early semester workshops that are aimed at anticipating the initial TA experience. Their definition of intensive programs can be enlarged to include such activities as weekend training programs, week long summer courses, etc. The advantages of intensive programs are numerous, such as building esprit de corps and providing basic skills assessment and training before possibly damaging or demoralizing (for both teacher and student) classroom experience. In addition, intensive programs can serve to orient new graduate students to the institution and can also accommodate a large number of students.

However, because intensive programs anticipate the TA experience, this may occur at a time when students cannot relate to the issues addressed. Moreover, the training experience is brief; there is often no follow-up; seldom any emphasis on skill development; and such programs may actually provide a false sense of security or competence for new teaching assistants. Thus, another training format may be needed to compensate for the shortcomings of intensive training programs. 
In this context, Hiiemae et al. (1991) define protracted training as a longterm program that is usually spread out over a whole semester. Protracted training programs can include such activities as mentoring programs and discussion groups; however, Hiiemae et al. (1991) suggest that they are most often seen in the format of semester length courses. Such protracted training can build on, expand, and go beyond the initial intensive training experience at a time when students are actively involved in their role as teaching assistants.

In addition to being quantitatively different from intensive training programs, protracted training may also address different issues. For example, protracted training can include such advanced topics as course design, preparation of syllabi, and principles of psychometrics (Ambrose, 1991). It can be argued that these topics are more advanced and perhaps more specifically aimed at preparing graduate students for academia. This is consistent with the fact that such courses often include issues related to the philosophy of higher education, professionalism, and ethics.

Hiiemae et al. (1991) argue that, although different in quantity and quality, the intensive and protracted approaches are not mutually exclusive options: a program can begin with an intensive "total immersion" component and continue throughout the academic year. Similarly, Schoem, Carlton, Gates, and Black (1991) explain that multiple training modes, such as full-day workshops and semester-long courses, are important ingredients of successful graduate student training. Thus, there appears to be value in both approaches to training in higher education.

Having said this, however, more attention has been given to intensive approaches to TA training. Piccinin et al. (1993) recently conducted a study aimed at determining the state of the art of TA training programs in Canada and concluded from their survey that the TA day was the most popular type of training program. Similarly, Buerkel-Rothfuss and Gray (1991) also concluded from their American survey that the prototype of training was a one-day intensive training session.

Given that intensive approaches to training are most prevalent, it is not surprising that the frequency and nature of these approaches to training have been well documented for American (Buerkel-Rothfuss \& Gray, 1991) and Canadian universities (Piccinin et al., 1993). However, there is little literature to be found on the frequency and nature of protracted approaches to training graduate students for teaching. Although Piccinin et al. (1993) reported that protracted approaches to TA training are available to students in some Canadian universities, and personal communications have revealed that such training programs 
exist in the United States and other countries (eg. Australia), no detailed studies of protracted training could be found.

In this context, the purpose of this investigation was to document the current state of affairs in Canada regarding semester length credit courses on teaching in higher education offered to graduate students. The implications of these findings will be considered, and some suggestions are proposed which may be useful to universities considering the establishment of such courses.

\section{Method}

Letters were sent to all Canadian institutions that were surveyed for an earlier study by Piccinin et al. (1993), except those which reported that they did not have graduate teaching assistants $(\underline{\mathrm{N}}=37)$. Specifically, we requested descriptions of any courses, whether short or long, optional or compulsory, with or without credit, aimed at the preparation of graduate students for teaching in higher education. Follow-up letters were sent and personal communications were held with those institutions which seemed to have what might be considered protracted training in the form of credit courses.

\section{Results}

At the time of the survey, the following institutions offered university approved semester length credit courses for graduate students on teaching in higher education: Dalhousie, McGill, Victoria, York, Western Ontario, and Windsor.' McMaster University recently submitted a proposal for such a course to their School of Graduate Studies and is awaiting a reply. At the time of writing, two other universities were known to be discussing the possibility of initiating such a course, namely the University of Ottawa and Queens University. Detailed outlines of the actual courses were obtained such that the following results and discussion are based on the responses of the six institutions which have approved credit courses.

We will now turn to a detailed presentation of the information contained in the identified course outlines under the following rubrics: 1) target population, 2) sponsorship, 3) course format, 4) instructor, 5) stated objectives, 6) topics, and 7) assessment and grading.

\section{Target Population}

Five of the six institutions clearly stated that the course was open to all graduate students. The University of Victoria stated that the course was specifically intended for: "those who have embarked on a career path that will enable you to 
teach in college and university settings". In virtually all cases enrolment was limited to approximately 20. Two of the institutions (Western Ontario and Windsor) specified that there would be approximately equal representation in enrolment from each of the four divisions of the Faculty of Graduate Studies.

\section{Sponsorship}

In terms of course sponsors, three courses were offered by the department/ School of Education (Dalhousie, McGill, and Victoria), whereas three courses were sponsored by the Faculty or School of Graduate Studies (York, Western Ontario, and Windsor). Sponsorship was determined by examining the course codes. All courses with EDU labels were seen as being sponsored by the Faculty of Education; all other courses had a Graduate Studies code.

\section{Course Format}

All courses were the equivalent of a typical semester course, ranging from 33 hours to 48 hours of instruction. Four of the courses were given during the academic year and two were offered during the summer term (York and Western Ontario). All courses were credited; however, students from McGill University also had the option of taking the course without credit. One institution (Western Ontario) further stipulated that the credits obtained from the course could not be substituted for departmental requirements. Finally, none of the courses provided were mandatory.

\section{Instructor}

Five of the six institutions have one course instructor with full responsibility. However, this does not preclude the possibility that these instructors could also invite guest presenters/speakers. The instructors for these courses were from different departments: two instructors were from the School of Education (McGill and Dalhousie), one instructor was a psychologist from Counselling Services (Victoria), and two instructors were from the Centre for the Support of Teaching (Windsor and York). At the University of Western Ontario there was one assigned course coordinator (a psychologist), and nine instructors appointed to teach specific topics in their areas of expertise. It was noted that, in all cases, the main instructor/coordinator was directly or indirectly related to the institution's instructional development or teaching centre. In addition, all instructors were experienced university teachers with backgrounds primarily in Psychology and/or Education. 


\section{Stated Objectives}

An examination of the course outlines revealed that the stated course objectives fall into three categories: 1) theory and research on learning and teaching, 2) development of skills in applied teaching, and 3) philosophy of higher education and professional and ethical issues. The results indicated that five of the six institutions provide substantial material in all three areas.

The nature of the course at Dalhousie is unique as it tends to be more theoretical and emphasizes teaching related issues in higher education. Specifically, the course outline states that:

...the course provides a forum for graduate students across campus to read, to reflect, to discuss and to write about issues related to university 'pedagogy.' This is not a teaching methods course.

\section{Topics}

Bort and Buerkel-Rothfuss (1991) developed a taxonomy of general categories of the content of TA training. Although this taxonomy was derived from intensive training programs for teaching assistants, it is nevertheless the only taxonomy derived from a systematic program content analysis. To make it more applicable to protracted training courses, modifications were made to the taxonomy. Their categories were grouped according to whether they centered around four different content areas: 1) research and theory, 2) skill building, 3) professional attitude and philosophy about teaching and learning in higher education, and 4) general orientation activities.

As previously mentioned, Dalhousie offers a unique program which emphasizes theoretical issues related to higher education. Thus, the content of its course was not examined based on the above mentioned taxonomy.

All other universities provide instruction in the areas of research and theory of teaching. For example, the topics of course development and design, including writing course objectives and preparing syllabi, theories of learning and teaching as well as topics in educational measurement, such as preparing assignments, tests, exams and evaluating students, were covered.

Similarly, all institutions also provide teaching skills training. For example, issues such as leading discussions, lecturing, design and use of visual aids, building rapport and building classroom climate were addressed and students are given opportunities to practice teaching skills and receive individually tailored feedback.

With respect to attitudes and philosophies regarding higher education, all courses contained some content in this area to varying degrees. In this domain, 
issues such as the goals of higher education, philosophy of teaching, faculty development, ethics in university teaching, and sexual harassment were addressed.

Finally, five of the six universities dealt with orientation issues, such as TA evaluation and feedback, university academic policies, help for the foreign student, as well as providing information on university instructional resources, library, computer services, and the centre for university teaching or instructional development.

\section{Assessment and grading}

In terms of assessment, the survey indicates that in three cases a numerical or letter grade was assigned for the course (Dalhousie, York, and Victoria); one course functioned on a Pass or Fail basis (McGill); and two courses assigned a pass, pass with distinction, or fail grade (Western Ontario and Windsor). Courses provided different evaluation formats, including critiques on assigned readings, major term papers, participation points, microteaching assignments, and book reviews. One university included a final take-home exam (Western Ontario) and two courses required students to design an instructional plan (McGill and Victoria). One course negotiated the method of evaluation on an individual basis (York).

\section{Discussion}

The purpose of this paper was to present the findings of a recent survey of credit courses on university teaching for graduate students (protracted TA training) offered in Canadian universities. Six institutions that offer such programs were identified, and there are two other universities that are known to be considering such courses. ${ }^{2}$ The small number of institutions currently offering semesterlength courses confirms the results of past research (Piccinin et al. , 1993), indicating that credited and protracted approaches to the training of teaching assistants are not yet common practice.

Since it was found that all courses currently available in Canadian universities target all graduate TAs, it can be concluded that available protracted training in Canada adopts a centralized training approach which targets students in general. This is different from opting for department-specific training which would be considered decentralized. Furthermore, the fact that $50 \%$ of the courses were sponsored by Graduate Studies reflects the observation that courses are indeed centrally organized. Courses sponsored by the School of Graduate Studies are also seen as reflecting the importance graduate schools attach to training for teaching in higher education. 
Hiiemae et al. (1991) have discussed the issue of centralization/decentralization of training programs in higher education. They recommended a centrally organized and budgeted program with department specific components. They argue that one advantage of centralized all-university programs is that all TAs have the same training experience. Furthermore, they also indicate that the main focus of such courses tends to be on generic rather than discipline specific skills. This is particularly interesting as one of the purposes of protracted training is to prepare students for academia, which requires general knowledge of teaching theory and practice in higher education.

The findings of this survey indicate, however, that none of the Canadian universities offering these courses reported providing much in the way of department specific components to their training. This could be viewed as a drawback as some disciplines do indeed require the combination of general with discipline specific training. To illustrate this point, consider the graduate student TA in the Faculty of Science. He/she needs to be equipped with two types of skills in order to be a good teaching assistant. First, basic generic skills regarding teaching are necessary, and second, specific skills regarding laboratories are also necessary. Hiiemae et al. (1991) would recommend that the first set of skills be learned through centralized training programs, and the second set of skills be learned through decentralized, department specific training programs.

All courses were the equivalent of a semester long course. All courses reported here were offered for credit, with one institution offering the choice of registering for or without credit. The practice of crediting courses for graduate students is a valuable one. It serves as incentive for students to enrol in such a course, and it also communicates that teaching is a valued activity in the institution. Personal communications with individuals involved in the establishment of these courses also conveyed support for the practice of crediting students as a way of recognizing the time and energy that are required by both instructors and students of such courses.

None of the courses offered were mandatory. This finding is consistent with a recent study of Canadian universities that found that only $28 \%$ percent have mandatory training, whether the training is intensive or protracted (Piccinin et al. , 1993). Similar findings were reported in a recent survey of U.S. universities in which only $13 \%$ of universities indicated that attendance at TA training was mandatory (Buerkel-Rothfuss \& Gray, 1991).

It should be noted that these statistics go against current opinion of some authors. For example, Hiiemae et al. (1991) recommend that training programs involve a mandatory core, with some choice of activities to allow for differing 
student needs and experience. They consider that a mandatory program can provide all new TAs with a foundation based on a core of common knowledge. They also feel strongly that optional programs allow students to self-select: those who participate are likely those who take their teaching role seriously and are good classroom teachers, while those who choose not to attend are likely those for whom the program would be especially valuable. This position is similar to the one adopted by the Report of the Association of Universities and Colleges Task Force on the Report of the Commission of Inquiry on Canadian University Education (1992).

On the topic of course instructor, the findings indicate that although staffing patterns depended on the institution, all principal instructors were highly experienced university teachers directly or indirectly related to the institution's instructional development or teaching centre. This is not surprising in light of the fact that the mandate, goals, and objectives of such centres are consistent with those of courses on higher education.

With the exception of Dalhousie University, the objectives of all courses were related to 1) theory and research on learning and teaching, 2) development of applied teaching skills, and 3) philosophy of higher education and professional and ethical issues. These findings are consistent with the contention of Hiiemae et al. (1991) that well planned training programs should focus on two objectives. The first should be to enhance the quality of undergraduate teaching: TAs should develop classroom confidence, a clear sense of their pedagogical role including the various instructional formats available to them, good verbal and interpersonal skills, and an understanding of the full range of their responsibilities to their students as well as the variety of demands student make on them. The second objective should be to enhance the quality of the graduate student experience. Graduate students need to be prepared for a career in the professoriate; they need to recognize the importance of the teaching mission of the academy; they need to develop a sense of community beyond the confines of their disciplines; and they need to learn time management and communications skills.

Similarly, Belenky, Clinchy, Goldberger, and Tarule (1986) have indicated that TA training encompasses different aspects: theoretical understanding, skills training, behaviour awareness, and the development of a sense of self as an academic. The findings suggest that the objectives of the majority of Canadian universities clearly encompass both the objectives of Hiiemae et al. (1991) and of Belenkey et al. (1986).

The results also indicate that the course topics were congruent with the stated objective, such that most courses focus on theory and research on teaching in higher education, offer skill building opportunities, and address 
professional issues, philosophy of higher education, and orientation issues. Having said this, however, it is important to note that the content of these courses is mostly related to theory and research on teaching in higher education, and less attention is given to the philosophy of higher education and ethical and professional issues.

These results are consistent with McKeachie's (1986) view that the need for skills training has been clearly identified, but that it is also extremely important and a challenge to encourage greater interest in, and awareness of, pedagogy per se. On this point, it can be argued that Dalhousie is the institution that provides most emphasis on these issues.

Finally, methods of assessment varied among institutions, offering a range of methods, including readings, term papers, participation, microteaching, book reviews, and course design. Three of the courses were graded with a numerical or letter grade and three were graded on a Pass/Fail basis. Upon consideration, it can be stated that although numerical or letter grades meet certain administrative requirements, their actual meaning is difficult to interpret within the context of such courses. This is particularly pertinent in light of the fact that these courses cannot typically be substituted for students' program requirements. Thus, grading courses by providing a Pass/Fail system may be the most appropriate method of evaluation.

\section{Recommendations}

Following the examination of the organization, content, and format of credit courses on university teaching for graduate students in Canadian universities, what recommendations can be provided for institutions which are considering such courses? First, the establishment of such courses is strongly encouraged. Second, there are clear advantages to having centrally organized courses. As suggested by Fink and Everley (1991), students and universities can profit from increased cooperation among departments. Thus, bringing faculty together in a university-wide teaching preparation program is a step toward achieving this goal.

Third, it is argued that such courses should have the visible support and sponsorship of the Faculty/School of Graduate Studies. This is important for both philosophical and practical reasons. Philosophically, sponsorship by Graduate Studies conveys a university-wide commitment to teaching in higher education. As suggested by Hiiemae et al. (1991), if a university believes that the purpose of teaching in higher education is to prepare students for academic and scholarly careers, then an ideal home for this type of program is Graduate 
Studies. Practically, sponsorship by Graduate Studies can ensure administrative advantages as most issues related to all graduate students are processed through Graduate Studies.

Fourth, we contend that there would be advantages to having primary responsibility for such courses with the university's instructional development or teaching centre where its mission is consistent with the purposes of the course. Fifth, it would be most effective if such courses were available to all graduate students. Indeed, all graduate students, whether TA or not, could benefit from thorough preparation for teaching or research before entering an academic career. Furthermore, providing training to all graduate students would permit equal possibilities for training in higher education, and would help ensure a common teaching background for all teaching assistants within a university.

What should be the format of these courses? The equivalent of at least a semester long course would be beneficial in that it would allow more time to cover the important issues regarding teaching in higher education. The practice of crediting the courses has great value as an incentive for graduate students, as well as having no additional fees imposed for registering in such courses. Having said this, however, we note that the training experience may be more valuable if only interested students participate. Therefore, it may be preferable if the courses were not compulsory. The risk associated with this practice, however, is that those who will participate are those who take their teaching role seriously and are good classroom teachers, while those who choose not to attend are those for whom the program would be of maximum value.

In order to maximize the quality of the training received, it would be advantageous if the course was taught by experienced professors who are directly or indirectly involved in instructional development. This would be beneficial in that resources would be available and as the impetus for such courses is consistent with the philosophy of instructional development. As a way of providing well rounded training in the area of teaching in higher education, it would be best if the objectives of the courses included theory and research in higher education, applied skills, and philosophy of higher education and professional issues. The content of the course could, therefore, reflect the recommended objectives. Finally, because of the nature of training courses, grading students on a Pass/Fail basis may be more appropriate, and the method of assessment could include both theoretical and applied components. 


\section{Notes}

1 One university (Manitoba) provides a course on university teaching for graduate students which was, at the time of the survey, offered on a non-credit basis. For this reason, it is not included in the results which follow. As a result of personal communication, it is clear that another course is now offered for credit.

2 Credit courses are now approved and offered at McMaster University and the University of Ottawa. Three other universities (York, McGill and University of New Brunswick) are known to be planning or introducing 15 credit diploma programmes in university teaching.

\section{References}

Ambrose, S. A. (1989). From graduate student to faculty member: Teaching Ph.D. candidates to teach. In J. D. Nyquist, R. D. Abbott, \& D. H. Wulff (Eds.), Teaching Assistant Training in the 1990s (pp. 7-13). San Francisco: Jossey-Bass Publishers.

Andrews, J. D. (1985). Strengthening the teaching assistant faculty. In New Directions for Teaching and Learning (Vol. 22). San Francisco: Jossey-Bass Publishers.

Belenky, M. F., Clinchy, B. M., Goldberger, N. R., \& Tarule, J. M. (1986). Women's way of knowing. New York: Basic Books.

Bort, M., \& Buerkel-Rothfuss, N. L. (1991). A content analysis of TA training materials. In J. D. Nyquist, R. D. Abbott, D. H. Wulff, \& J. Sprague (Eds.), Preparing the professoriate of tomorrow to teach (pp. 243-251). Iowa: Kendall/Hunt Publishing.

Buerkel-Rothfuss, N. L., \& Gray, P. L. (1991). Teaching assistant training: The view from the top. In J. D. Nyquist, R. D. Abbott, D. H. Wulff, \& J. Sprague (Eds.), Preparing the professoriate of tomorrow to teach (pp. 29-39). Iowa: Kendall/Hunt Publishing.

Commission of Inquiry on Canadian Higher Education. (1992). Association of University and Colleges Task Force Report

Fink, D., \& Everley, M. (1991). The University of Oklahoma's Teaching Preparation Project: A final evaluation and report. Unpublished report.

Hiiemae, K., Lambert, L., \& Hayes, D. (1991). How to establish and run a comprehensive teaching assistant training program. In J. D. Nyquist, R. D. Abbott, D. H. Wulff, \& J. Sprague (Eds.), Preparing the professoriate of tomorrow to teach (pp. 123-134). Iowa: Kendall/Hunt Publishing.

McKeachie, W. J. (1986). Teaching Tips (8th Edition). Lexington, MA: D.C. Heath.

Nyquist, J. D., Abbott, R. D., \& Wulff, D. H. (1989). The challenge of TA training in the 1990s. In J. D. Nyquist, R. D. Abbott, \& D. H. Wulff (Eds.), Teaching Assistant Training in the 1990s (pp. 7-13). San Francisco: Jossey-Bass Publishers.

Nyquist, J. D., Abbott, R. D., Wulff, D. H., \& Sprague, J. (1991). Preparing the professoriate of tomorrow to teach. Iowa: Kendall/Hunt Publishing.

Piccinin, S., Farquharson, A. \& Mihu, E. (1993). Teaching Assistants in Canadian Universities: An Unknown Resource. Canadian Journal of Higher Education, 23(2), 104-117. 
Schoem, D., Carlton, S., Gates, B., \& Black, B. (1991). Developing and implementing a college-wide TA training program at the University of Michigan. In J. D. Nyquist, R. D. Abbott, Wulff, D. H., \& J. Sprague (Eds.), Preparing the professoriate of tomorrow to teach (pp. 150-156). Iowa: Kendall/Hunt Publishing.

Sheridan, J. D. (1991). A proactive approach to graduate teaching assistants in the research university: One graduate dean's perspective. In J. D. Nyquist, R. D. Abbott, Wulff, D. H., \& J. Sprague (Eds.), Preparing the professoriate of tomorrow to teach (pp. 24-28). Iowa: Kendall/Hunt Publishing.

Smith, S.L. (1991). Report of the Commission of Inquiry on Canadian Higher Education. Ottawa: Association of Universities and Colleges of Canada.

Wilkening, L. L. (1991). Teaching assistants: Training for the Professoriate. In J. D. Nyquist, R. D. Abbott, D. H. Wulff, \& J. Sprague (Eds.), Preparing the professoriate of tomorrow to teach (pp. 12-16). Iowa: Kendall/Hunt Publishing. 